\title{
GEOPHYSICAL INVESTIGATIONS AT NAFPLION CITY, GREECE. HYDROGEOLOGICAL IMPLICATION
}

\author{
Karmis P., D., Giannoulopoulos P., Tsombos P. \\ Institute of Geology and Mineral Exploration(IGME), S. Loui 1, 3rd Entrance Olympic Village, Acharnae \\ 136 77, Greece
}

\begin{abstract}
The application of selected geophysical methods within the framework of an Urban Geology investigation program performed by IGME at Nafplion city, contributed to the overall geo-scientific characterization of the study area. The methodology adopted included the application of Time Domain Electromagnetic, Electrical resistivity tomography, Gravity and Seismic Crosshole surveys. The results of the geophysical investigation provided quantitative information regarding the distribution of seawater intrusion in the area and determined factors controlling its extent within the investigated region. The intrusion may occur in three distinct horizons. The first within the shallow unconfined aquifer within the top 12 meters of fluvial deposits showing values of electrical conductivity in the range of 1 and 4 Siemens/m, corresponding to TDS values between 5000 and $20000 \mathrm{mg} / \mathrm{L}$, as determined by the TEM surveys. Lower conductivity values between 0.3 and 1 Siemens/m are found within the second aquifer occurring between 15 and 45 meters. Similar order of conductivity values are found within the deeper horizon, lying below 45 meters depth, attributed also to seawater intrusion mainly in carbonate formations. Areas of fresh groundwater, were delineated by a combination of TEM, ERT and gravity methods. These areas are structurally controlled by faults and the presence of impermeable flysch overlying the limestone formation.
\end{abstract}

Key words: Geophysical techniques, salinization, electrical conductivity.

\section{Introduction}

The present paper deals with the results of the geophysical surveys carried out in 2007-2008 within the urban area of Nafplio, within the framework of the project Urban Geology undertaken by IGME. The program of geophysical surveys included Gravity, Electrical resistivity tomography (ERT), Transient Electromagnetic soundings (TEM) and seismic crosshole tests. Information derived by Gravity data is complimentary to TEM and ERT

The results of the geophysical investigations provided quantitative information regarding the geological structure and the distribution of saline water intrusion in the area and determined factors controlling its lateral extent. The Argos plain has suffered serious groundwater degradation in recent years, due to the seawater intrusion which mainly occurred during the second half of the last century. The application of TEM and ERT techniques can supply information regarding the extent of this phenomenon and to delineate aquifers with respect to their salinization. 


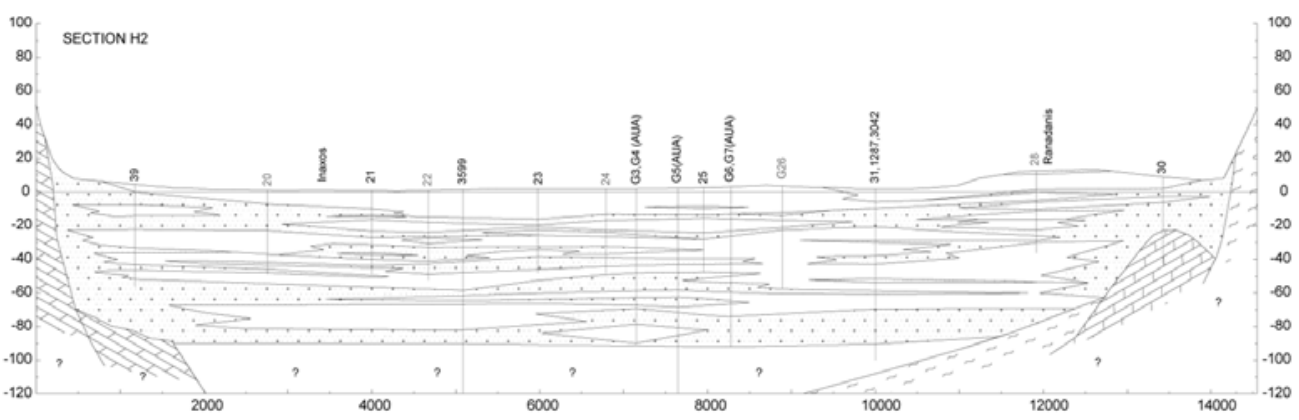

Fig. 1: A representative hydrostratigraphic section (west - east) of the alluvial deposits of Argos plain (Giannoulopoulos, 2000, 2001).

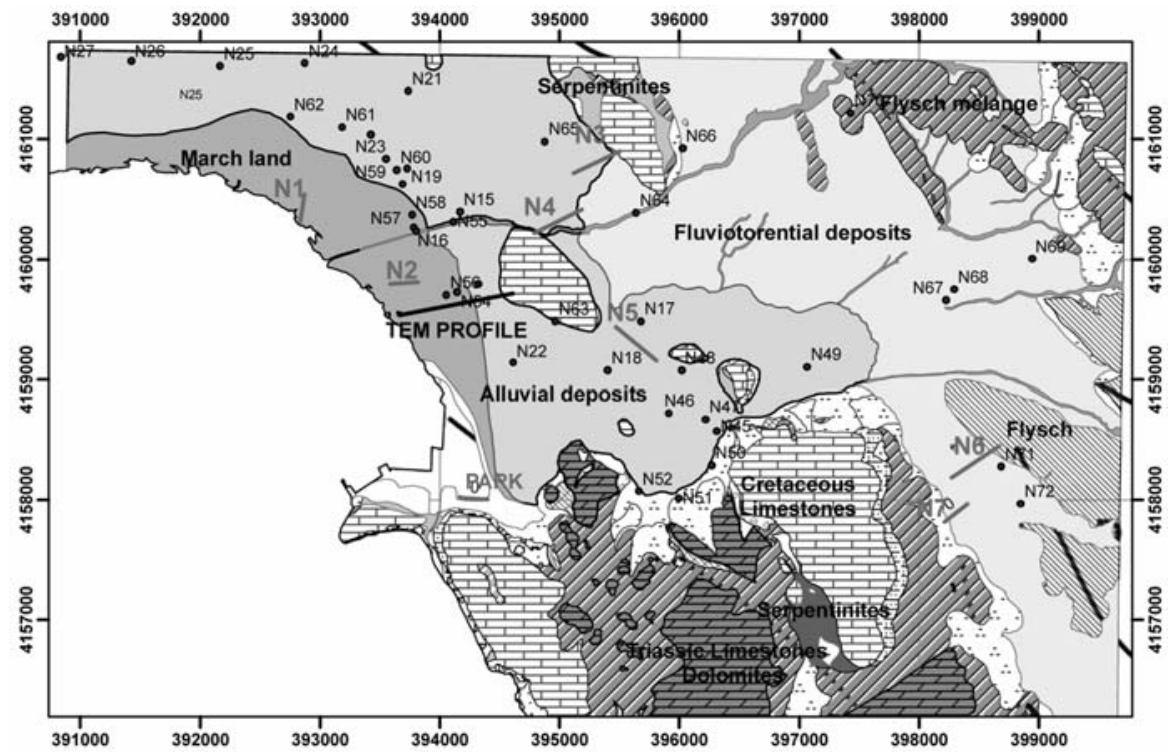

Fig. 2: Geological map of the investigated area (A.Fotiades, D.Metropoulos, 2008) . The resisistivity tomography lines are coloured red. The numbered dots indicate the location of TEM soundings.

\section{Geological and hydrostratigraphic setting}

The regional geology of the Argos plain is composed of Quaternary alluvial deposits, composed by alternations of fine and coarse sediments such as clays, marls, silty sands and silty-clayey layers and fluvial deposits while at the outskirts of the plain those sediments are transitionally surrounded by alluvial fans constituting a "piedmont" type of deposition. The underlying bedrock of the plain is made up by alpine and post-alpine sediments, such as flysch, limestone and Neogene marl conglomerates (Giannoulopoulos, 2000,2001). The investigation area (see Fig. 2, 3) is formed by alluvial, mainly lagoonal deposits, overlying flysch and limestone formations, locally outcropped and historically attracting well known Mycenaean settlements such us Tyrins

With regards to groundwater regime, within the Quaternary deposits, successive groundwater 


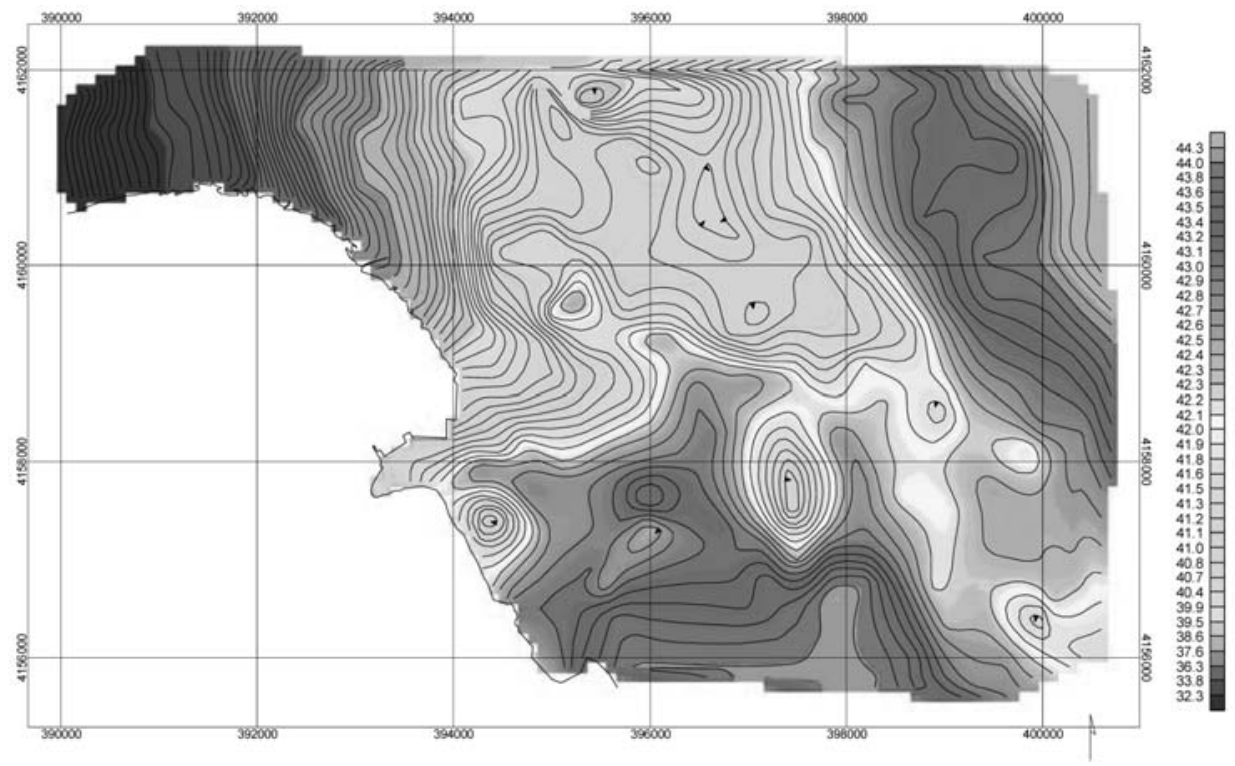

Fig. 3: Bouguer map of Nafplio area

aquifers are developed, being regionally overexploited through numerous dug wells and boreholes. This resulted to a considerable seawater encroachment in recent years. Within some parts of the investigation area, a weak and shallow unconfined coastal aquifer prevails, which is underlain by a succession of deeper confined aquifers separated by layers of fine sediments.

\section{Geophysical investigations}

The geophysical techniques aimed to the detection of the bedrock relief, the major structural and hydrostratigraphic elements and also to assess the extent of the sea intrusion in the area.

\section{Gravity survey}

The gravity survey covered an area of $35 \mathrm{~km}^{2}$ with 270 stations, conducted with a Scintrex CG-5 gravity meter.

From the Bouguer map of Fig. 3 a residual gravity map is extracted (Fig. 4) and overlain on the geological map. The positive anomalies GP1, GP2, GP3 are associated with the Cretaceous Limestone outcrops in the area. The anomalies GP4 and GP5 are associated with Triassic Limestones belonging to the basement. The negative anomalies GN1, GN2 and GN3 form a tectonic graben, bounded to the SW by a well known fault. Another NW-SE striking lineament is observed to the further south of the positive anomaly GP1, possibly associated with a second fault.

\section{Electrical resistivity tomography (ERT)}

The ERT method is the most commonly used 2D resistivity imaging method in recent years. This powerful method nowadays is being employed on a routine basis in various configurations with multielectrode arrays (48 electrodes), with spacings up to $20 \mathrm{~m}$, reaching investigation depths of $200 \mathrm{~m}$. 


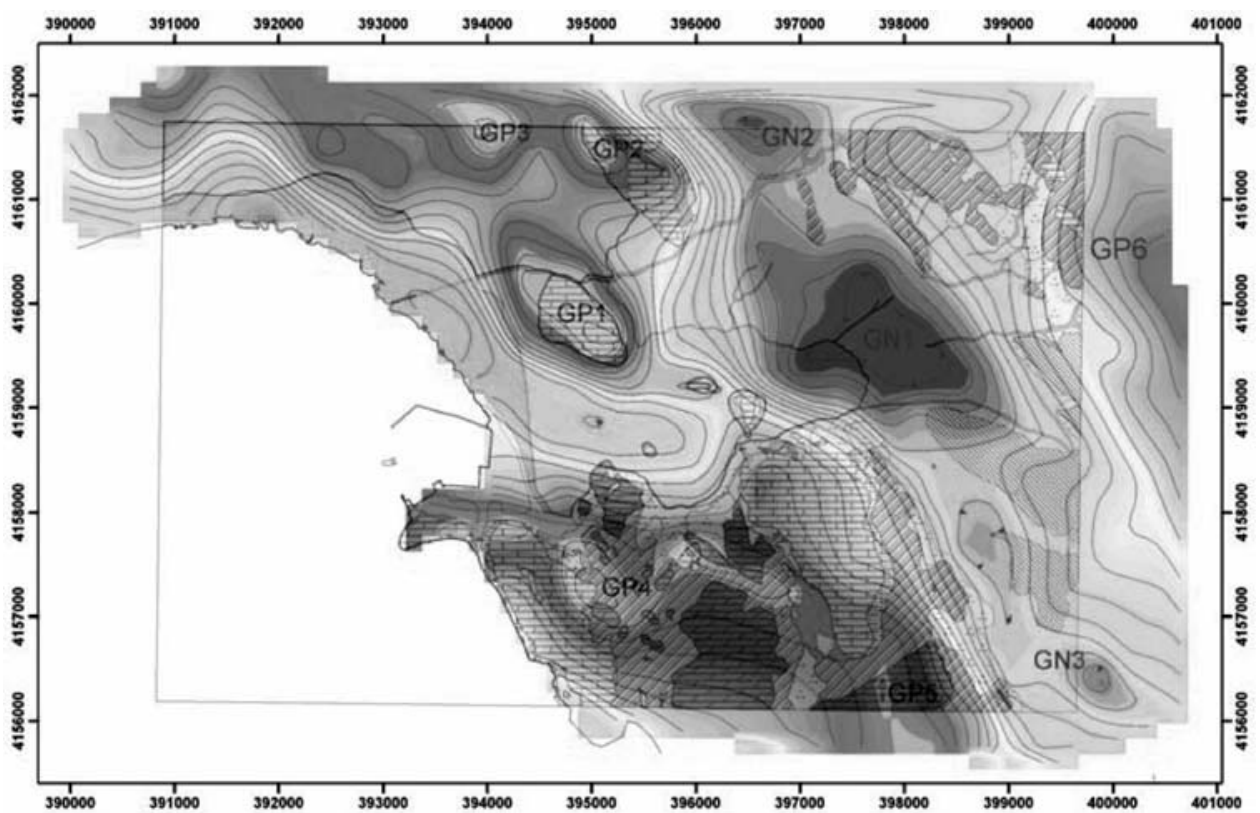

Fig. 4: Residual gravity map overlain on the geological map.
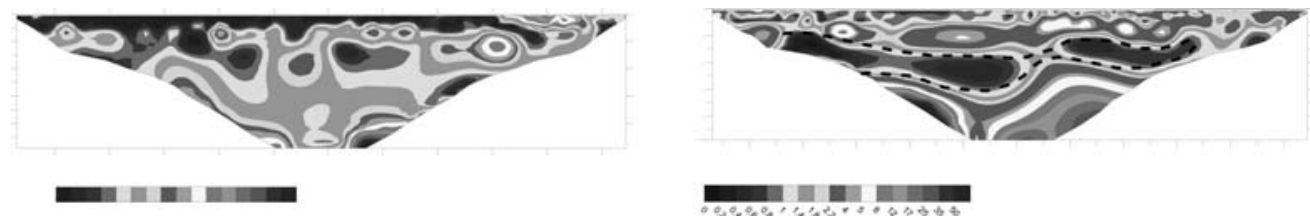

Fig. 5: Modeled resistivity sections of profiles N1 and N2.

Profiles N1 and N2 (Figure 5) were cited on the marsh land close to the coastline and were surveyed in order to evaluate the effect of salinization structure.

The results show the presence of sand-silty and clayey-silty sediments, saturated with solutions, of relatively high salinity. In fact, resistivity values even lower than $1 \Omega . \mathrm{m}$ are recorded from the land surface to the depth of $5 \mathrm{~m}$ (Profile N1). The presence of another low resistivity layer reaching depths of $30 \mathrm{~m}$ is evident on both profiles $\mathrm{N} 1$ and $\mathrm{N} 2$. The higher resisistivity values, of 20-40 $\Omega$.m, occurring deeper than 30 and $40 \mathrm{~m}$ are probably attributed to the underlying flysch bedrock (Fig. 5).

Bulk electrical resistivity values are generally dependent both of the rock - soil type and the pore fluid properties. Allowing for the very high conductivity of saline water with respect to the relatively moderate conductivity of prevailing sediments, it can be inferred that the recorded resistivity values reflect the order of salinity of pore water. This methodology calibrated on site specific data can be used as tool for the quantification and mapping of sweater intrusion in coastal areas.

Fishman and Friedman (1989) proposed an empirical relationship relating the electrical conductivity of aqueous solutions to the Total Dissolved Solids (TDS).

$$
\sigma(\mathrm{S} / \mathrm{m}) \approx \alpha \operatorname{TDS}(\mathrm{mg} / \mathrm{L})
$$



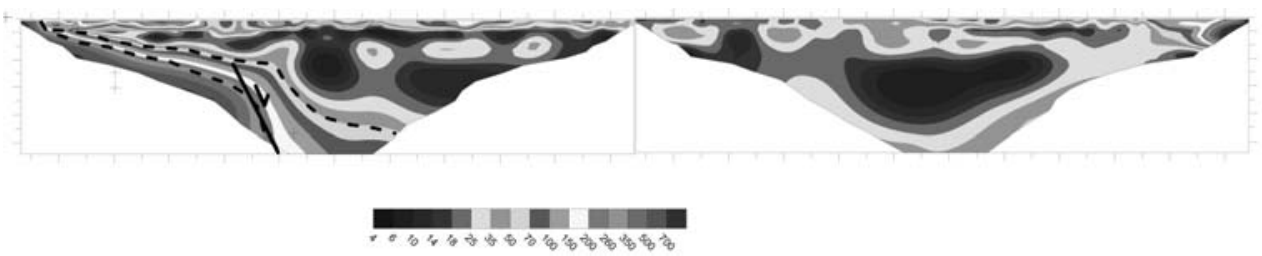

Fig. 6: Modeled resistivity sections of profiles N3 and N4
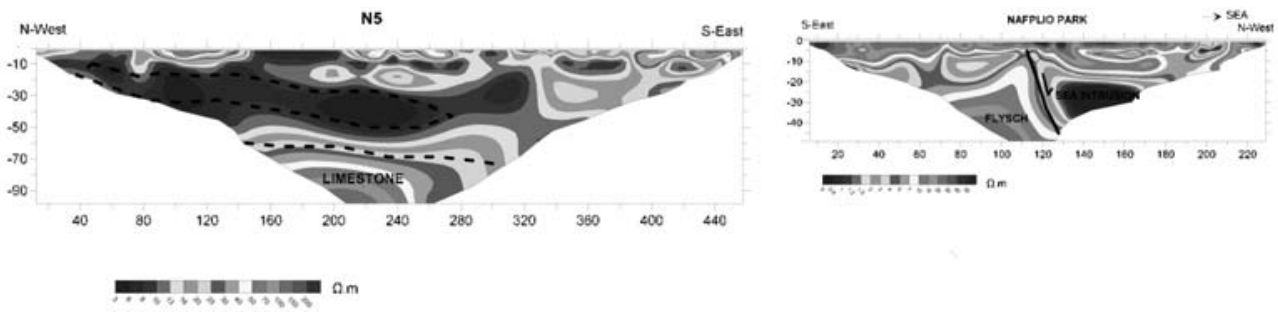

Fig. 7: Modeled resistivity sections of profiles N5 and Nafplio park.
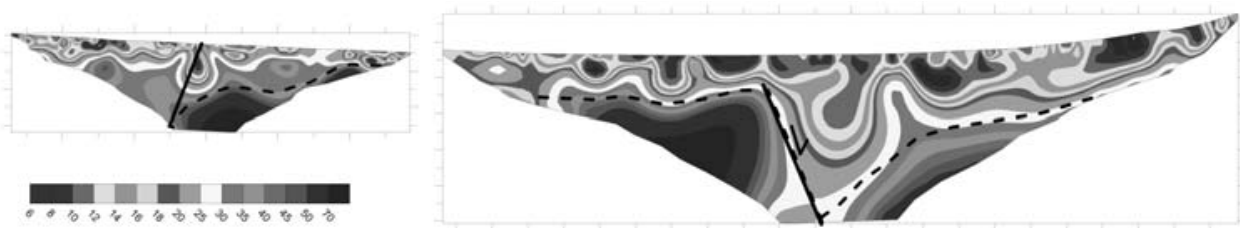

Fig. 8: Modeled resistivity sections of profiles N6 and N7.

where $\sigma$ is the electrical conductivity and $\alpha$ a constant ranging from $1.2 \times 10^{-4}$ to $2 \times 10^{-4}$. Making use of more that 250 chemical analyses data (Giannoulopoulos 2000) of major ions and calculating the corresponding TDS (Lloyd and Heathcote, 1985) it was found that $\boldsymbol{a}$ factor in the Aplain of Argos is $2 \times 10^{-4}$.

Assuming that the bulk electrical resistivity (or conductivity) is dominated by the pore fluid resistivity we use the above formula to calculate the groundwater salinity. An average value of $0.5 \Omega . \mathrm{m}$ was used, and a value of $\boldsymbol{\alpha}=2 \times 10^{-4}$ resulting to an average TDS value of $10.000 \mathrm{mg} / \mathrm{L}$.

In figure 6 profiles N3 and N4 were surveyed to test the possible occurrence of sea water intrusion in the valley formed between the two limestone hills. Resistivity values higher than $4 \Omega . m$ are recorded, and attributed to the confining marl and clayey sediments. There is no evidence of sea intrusion in this area. The geometry of the limestone constraining fault is clearly seen at the SW end of profile N4.

The modeled resistivity section of profile N5 (Fig.7) shows the occurrence of a conductive layer expanding mainly from 30 to $50 \mathrm{~m}$ depth being overlain by shallow layers of varying resistivity. Low resistivity values of 3-5 $\Omega . \mathrm{m}$ are attributed to clayey deposists. A resistive bedrock (Limestone) can be seen at a depth of $60 \mathrm{~m}$.

ERT was also conducted close to the centre of Nafplio city along the railway park and the resistivity section is shown in figure 7 . The presence of the seawater intrusion can be recognized with low 


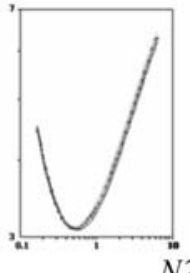

N29

$\begin{array}{clc}\text { Rho }(\Omega . \mathrm{m}) & \mathrm{d} & \text { Depth } \mathrm{m} \\ 10.5 & 12.6 & 12.6 \\ 2 & 23 & 46\end{array}$

15
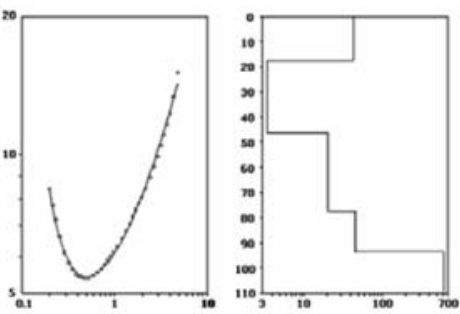

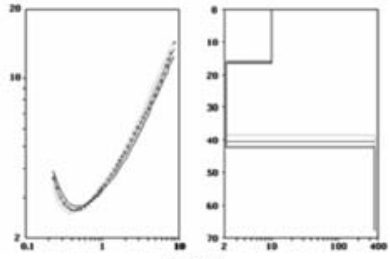

N27

$\begin{array}{ccc}\text { Rho }(\Omega . \mathrm{m}) & \mathrm{d} & \text { Depth }(\mathrm{m}) \\ 10 & 16 & 16 \\ 2 & 24 & 40\end{array}$

15

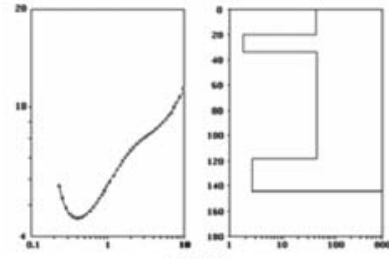

N26

$\begin{array}{ccc}\text { Rho }(\Omega . m) & \text { d } & \text { Depth }(\mathrm{m}) \\ 44 & 20 & 20 \\ 1.8 & 14 & 34 \\ 45 & 84 & 118 \\ 2.6 & 26 & 144 \\ 800 & & \end{array}$

\begin{tabular}{lll} 
Rho $(\Omega . \mathrm{m})$ & $\mathrm{d}$ & Depth $(\mathrm{m})$ \\
43 & 18 & 18 \\
3.4 & 29 & 47 \\
20 & 31 & 77 \\
45 & 16 & 93 \\
600 & & \\
\multicolumn{2}{c}{$N 25$}
\end{tabular}

Fig. 9: Examples of TEM soundings with interpretation models. Salinization affects only the shallow unconfined aquifer.

resistivity values of 0.3 to $1 \Omega . \mathrm{m}$. The seawater intrusion is bounded to the South-East by a fault zone. The presence of flysch bedrock to the SE limits the extent of the salinization.

The interpreted sections of figure 8 show the ERT results of profiles N6 and N7, sited at the tectonic graben shown on the gravity map of figure 4 . The occurrence of a fault can be clearly seen at the middle of profile N6. There is no indication of seawater intrusion in this area.

\section{Transient Electromagnetic Method (TEM)}

The TEM method has been developed mainly since the mid-1980's and tutorial articles specifically concerned with the method can be found in McNeill (1980), West and Macnae (1991), Ward and Hohmann(1987) and Zhdanov and Keller (1994). The method was originally developed for use in the mining industry to image electrical contrasts to depths of hundreds of meters. Compared with other mapping methods TEM is relatively cheap, has a large penetration depth and it gives both structrural and lithological information. Its strength lies on its ability to resolve and quantify lowresistivity layers, while resistivity values exceeding 80-120 $\Omega \mathrm{m}$ are not precisely determined.

TEM has a decreasing capability in resolving individual layers with depth, due to the diffusive nature of the method, meaning that succession of individual thin layers will commonly be averaged into one model layer. Due to difficulties in recording data at very early decay times the upper 10-20 m of the geoelectrical model are averaged into one layer. Recent improvements in transmitter turn-off time and sampling rate has improved resolution of the top 20 metres below surface making fastsampling TEM a useful tool in salinity surveys. It has been used as an airborne tool covering large areas in the search of paleochannels, hidden valleys and mapping salinity. 

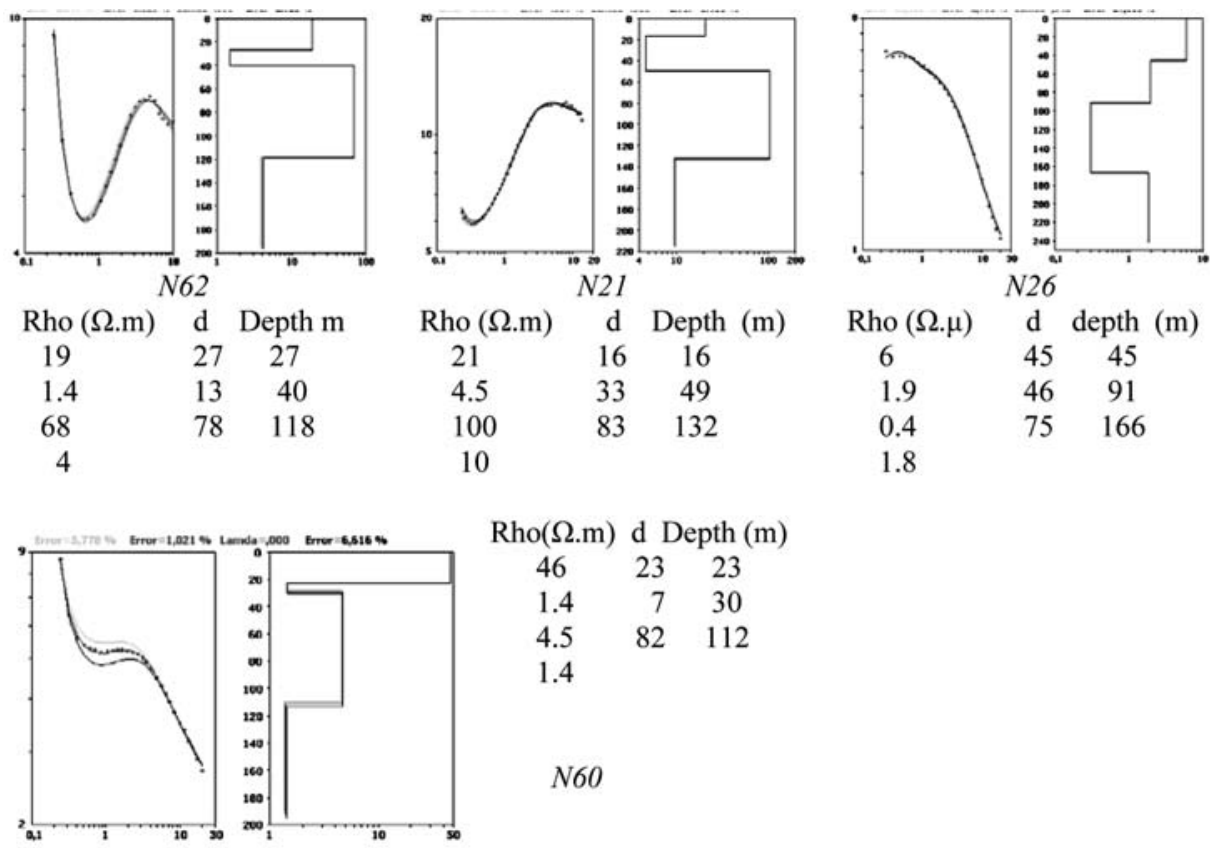

\begin{tabular}{crc} 
Rho $(\Omega . \mathrm{m})$ & \multicolumn{3}{c}{ d Depth $(\mathrm{m})$} \\
46 & 23 & 23 \\
1.4 & 7 & 30 \\
4.5 & 82 & 112 \\
1.4 & &
\end{tabular}

N60

Fig. 10: Sea intrusion occurs both near surface and at the porous basement.
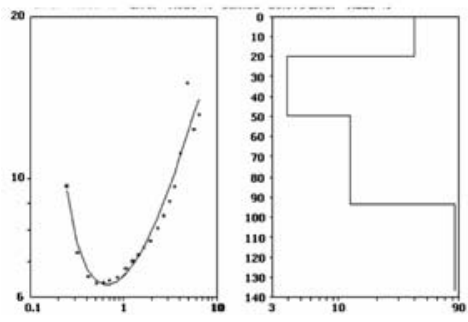

$\begin{array}{ccc}\text { Rho( }(\Omega . m) & \text { d } & \text { Depth }(\mathrm{m}) \\ 40 & 20 & 20 \\ 4 & 30 & 50 \\ 12 & 44 & 94 \\ 85 & & \\ & & \\ & & \\ \text { N55 } & & \end{array}$

Fig. 10 Limestone detected as basement with no salinization. Results are calibrated with borehole G10 which intersected limestone at $92 \mathrm{~m}$ depth.

A number of 70 TEM soundings was conducted in the project area using single loop configuration of $100 \times 100 \mathrm{~m}$ or $50 \times 50 \mathrm{~m}$ used simultaneously as transmitter and receiver.

All soundings have been processed and inverted using 1D modelling code (Karmis 2003).

The results are classified according to the degree of the saline intrusion and the nature of the basement.

In the following figures characteristic examples of TEM soundings are presented. In figure 9 the apparent resistivity versus time is plotted on the left part of each graph, along with the interpretation model on the right side. The sea intrusion is evident at all soundings in depths between 12 and $40 \mathrm{~m}$. The limited penetration depth, due to cultural noise, on N27 and N29 limits the interpretation depth of stratigraphy to the depth of flysh, whereas at soundings N25 and N26 limestone was detected as bedrock below flysch. A second category of TEM soundings show the salinization effect both on the surface layers (top $40 \mathrm{~m}$ ) and within the basement. By combining available drilling information, the porous formation of the basement is assigned to limestone which is also vulnerable to salinazition. 

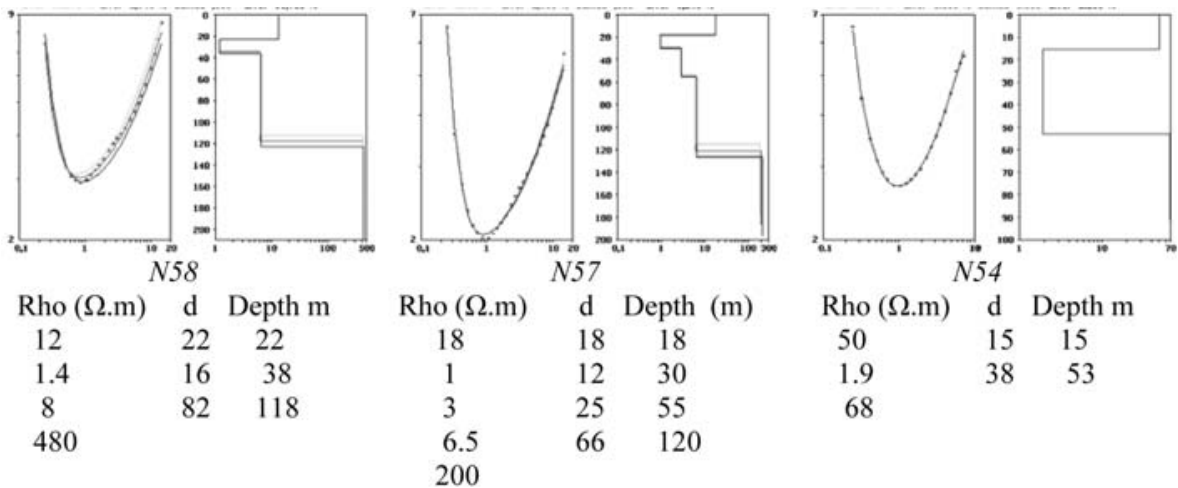

Rho $(\Omega . m) \quad$ d Depth $\mathrm{m}$

$50 \quad 15 \quad 15$

$1.9 \quad 38 \quad 53$

68

200

Fig. 11: TEM soundings N58 and N57 located limestone not affected by salinization.

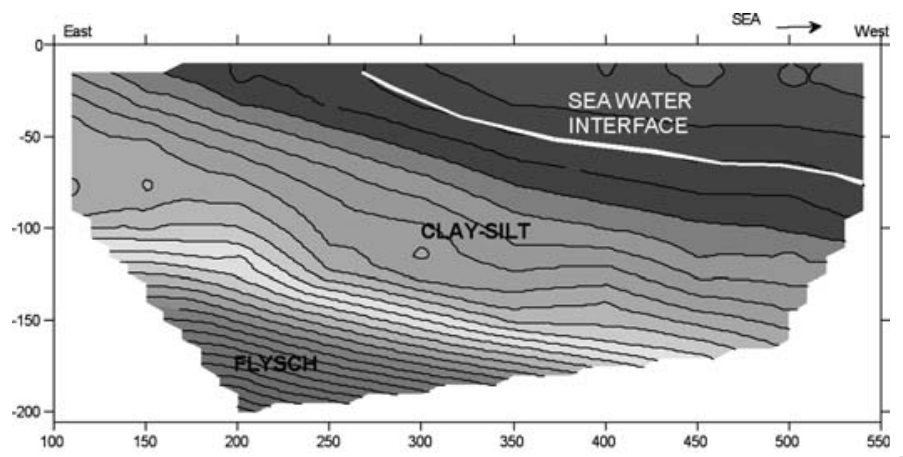

Fig. 12: TEM 2D resistivity section of TEM profile.

Sounding N62 (figure 10) shows the effect of seawater intrusion at depths between 27 and $40 \mathrm{~m}$. Below this depth a relatively resistive layer is detected, interpreted as sand layer. The salinization is also evident at the depth of $118 \mathrm{~m}$, which probably marks the top of the limestone. This interpretation is verified by the drilling results of borehole 3042, to the SE of N62, which intersected this limestone at the depth of $110 \mathrm{~m}$. Similar results are shown at N21, where the limestone can be seen at $132 \mathrm{~m}$ depth. The results of N26 indicate that seawater intrusion comes into effect at $45 \mathrm{~m}$ depth. The results of N60 are typical patterns of responses obtained over porous carbonate formation polluted by seawater intrusion. The presence of an aquifer affected by seawater intrusion is detected at $23 \mathrm{~m}$ depth. This aquifer is followed by a succession of fine clayey sediments, with the limestone at $112 \mathrm{~m}$ with resistivity of $1.4 \Omega . \mathrm{m}$, due to the saline water. The results of figure 11 show the presence of fresh - water carbonate layer. This is probably due to the presence of a flysch layer on top of the limestone which acts as a protecting barrier.

The N57 and N58 soundings show also the presence of limestone bedrock at depths of $120 \mathrm{~m}$. However, the penetration depth of N54 does not allow the detection of the limestone bedrock.

\section{TEM Profile}

The TEM profile was surveyed with a dense spacing of $50 \mathrm{~m}$ and a $50 \times 50 \mathrm{~m}$ loop. The results are shown in figure 12 . The interpretation model is a pseudo-2D section with resistivity and depth values are calculated per each decay channel, resulting to a dense and closely spaced dataset. 


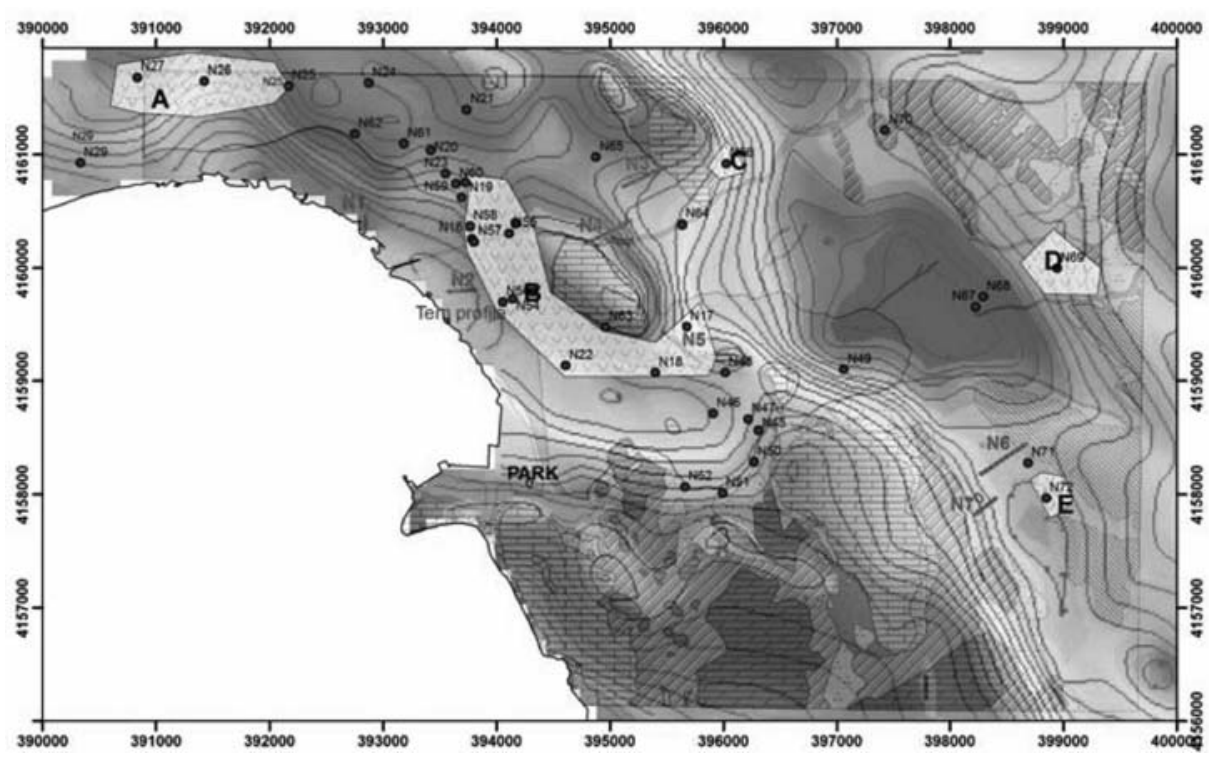

Fig. 13: Areas A, B, C, D and E with limited salinization pollution due to existence of impermeable cap layers above the carbonate basement.

The section shows the geologic succession gently dipping to the SouthWest at small angle. There is no indication of a fault in this line. The seawater intrusion is clearly recognized with resistivity values lower than $2 \Omega . m$. Below the shallow silty-clayey sediments the flysch layer is detected.

\section{Conclusions}

The application of the geophysical surveys added important new and detailed information to the construction of hydrostratigraphic models in coastal areas, giving a more comprehensive understanding of the formation of the subsurface layers and structures. Gravity survey provided general information on the subsurface structures, whereas the results of the ERT and TEM surveys show the importance of these methods in environmental and groundwater investigations in coastal areas. They constitute an effective tool for mapping the fresh -seawater interface in the alluvium and carbonate aquifer. They are particularly suitable for determining the resistivity and thickness of highly conductive targets such as clays and saline aquifers. Accordingly they can be used to map potential aquifer layers, recognized as sediments with relatively high resistivity.

The low resistivity sediments are indicative of low permeability deposits such as clays. These low permeability clayey layers may serve as protection against groundwater contamination caused by seepage of pollutants and seawater.

With regards to the particular results of the aforementioned geophysical surveys the effect of the sea water contamination is mainly identified within three horizons. The first is a shallow layer from surface to approximately 12 meters close to the coastline of the march land, with very low values of electrical resistivity below $1 \Omega$.m. These values, according to an empiric formula, correspond to TDS values in the range of 5000 and $10000 \mathrm{mg} / \mathrm{L}$. The second horizon corresponds to saturated sediments made of sand and gravel (confined aquifer) with resistivity values between 1 and $3 \Omega$.m located in relatively shallow depths between 15 and $40 \mathrm{~m}$. The third horizon has similar resistivity values at 
depths larger than 40 meters and corresponds to the porous formation (limestone) which is heavily polluted by the sea intrusion.

As a rule of thumb it can be stated that bulk resistivity values lower than $2 \Omega$.m correspond to saline water, where higher values between 2 and $4 \Omega$.m may be attributed either to various combinations between brackish water or to the lithology.

Occurrence of low-permeable layers such as flysch above the carbonate aquifers was detected in certain areas delineated in the map of figure 12. In areas A and B the seawater intrusion is limited only within the second horizon due to the presence of flysch overlying the deeper limestone. The flysch is gently dipping towards the sea and limits the effect of the sea intrusion to the limestone.

In areas $\mathrm{C}, \mathrm{D}$ and $\mathrm{E}$ sea intrusion is not observed. In this region fault discovered seen by gravity method, control the encroachment of seawater intrusion. The rest of the area is heavily polluted by the sea intrusion. The region between areas A and B and between B and Palamidi hill act as conduits for the salinization of the mainland.

The combined application of high resolution TEM and ERT surveys can be an effective tool for studying the effect of the sea-intrusion and map salinity changes.

\section{Acknowledgments}

This study was implemented in the frame of the project "Collection and Documentation of Geothematic Information for Urban Areas in Greece". Funded by Competiveness Priority Axis 7: Measure 7.3 and ERDF.

\section{References}

Giannoulopoulos P. Groundwater flow and mathematical models in the plain of Argos. Agricultural University of Athens, Department of Natural resources Development and Agr. Engineering. Unpublished Ph.D. Thesis. 362 p, 2000

Giannoulopulos P. Hydrostratigraphic conditions of the alluvial sediments of Argos Plain-Aquifer formations. Proceedings of the 9th Int. Congress of Greek Geol. Society, Vol 5, pp.1793-1800, 2001

Karmis P. Automatic interpretation of TEM data, PhD Thesis, University of Athens, p. 248, 2003

Lloyd J. and A. Heathcote. Natural Inorganic Hydrochemistry in Relation to Groundwater. Oxford University Press. 296 p., 1985

McNeill J.D. Applications of transient electromagnetic techniques, Geonics Ltd. Technical Note TN-17, 1980

McNeill J.D. Use of electromagnetic methods for groundwater studies. In Ward S.H.(Ed). Geotechnical and environmental problems 01. Society of Exploration Geophysicists, pp. 91-218, 1990

Rubin Y., Hubbard S. Hydrogeophysics Springer, p. 523, 2005

Ward S.H., Hohmann G.H. Electromagnetic theory for geophysical applications. In Nabighian, M.N. (Ed) Electromagnetic methods in Applied Geophysics, vol 2a, Society of Exploration Geophysicists, pp. 131-311, 1987

Zhadanov M.S., Keller G.V., The Geoelectrical Methods in Geophysical Exploration, Elsevier, 884 pp., 1994. 